\title{
Bryan, Joe y Denis Wood (2015). Weaponizing Maps. Indigenous Peoples and Counterinsurgency in the Americas. Nueva York: THE GUILFORd PRESS.
}

\author{
Sandra Cañas-Cuevas
}

$\mathrm{A}^{\mathrm{p}}$

partir de la controversia generada por el proyecto México Indígena a cargo del geógrafo estadounidense Peter Herlihy realizado en la Sierra de Juárez en Oaxaca, en el libro Weaponizing Maps. Indigenous Peoples and Counterinsurgency in the Americas se discute el papel contradictorio de los mapas, de su producción y uso. Para muchos pueblos y grupos indígenas, el mapeo de sus tierras es la base para el reconocimiento de sus derechos al territorio, la autodeterminación y el autogobierno. Al mismo tiempo, el mapeo también puede ser un medio para integrar territorios indígenas al mercado y a proyectos de seguridad y control militar.

Bryan y Wood nos relatan la historia del proyecto México Indígena, promovido por la Sociedad Americana de Geografía (American Geographical Society, AGS por sus siglas en inglés) a través de las Expediciones Bowman financiadas por la Oficina de Estudios Militares Extranjeros (Foreign Military Studies Office de Estados Unidos). Los autores realizan una genealogía histórica pormenorizada para explicar el proceso a partir del cual los mapas y el mapeo se han convertido en un arma política de doble filo. Esta revisión histórica va desde el colonialismo interno en Estados Unidos y su expansión internacional a través de las "guerras bananeras" en Centroamérica, hasta las batallas de la Guerra Fría y, más recientemente,

Sandra Cañas Cuevas. Centro de Investigaciones Multidisciplinarias sobre Chiapas y la Frontera Sur, de la Universidad Nacional Autónoma de México. Correo electrónico: mail@sandracanas.com, sancacue@ yahoo.com. las estrategias de contrainsurgencia puestas en marcha en diferentes partes del mundo. Asimismo, también trazan la historia del surgimiento de los mapas como arma de defensa de territorios indígenas en el continente americano. El libro consta de nueve capítulos, en los cuales se analiza la producción y uso de los mapas a partir de tres vertientes que con frecuencia se entrelazan: la vertiente militar, la vertiente académica y la vertiente indígena.

La vertiente académica desarrolla la conexión del proyecto México Indígena con la AGS. Esta sociedad estaba interesada en recuperar su papel y presencia en la academia anglosajona. Fundada en 1851 por neoyorkinos acaudalados, desde sus inicios la AGS estuvo interesada en la expansión del territorio y el comercio: "Se apoyaban expediciones de exploración con la expectativa no sólo de recolectar información científica, sino sobre todo datos de uso práctico para los mercaderes y misioneros" (p. 17, traducción propia). De acuerdo con los autores, la AGS ha sido más bien una organización con fachada académica, pero con fines imperialistas y expansionistas, carácter que ha mantenido hasta nuestros días. La AGS vio el proyecto México Indígena como una oportunidad para salir de la crisis en la que se encontraba, a partir del reclutamiento de geógrafos para colaborar con el ejército estadounidense. 
En lo que respecta a la vertiente militar, los autores explican el surgimiento de los mapas como arma expansionista o colonial a través de la presencia de marines en la región miskito de Nicaragua en 1910, en respuesta al interés geopolítico en el canal de Panamá para el aseguramiento de rutas comerciales. Esta experiencia de ocupación, argumentan, sentó las bases para el desarrollo de un modelo de guerra de contrainsurgencia para el cual la producción de mapas es una tarea clave. De acuerdo con los autores, este modelo combina sensibilidad política, diplomacia personal y un tipo de antropología militar:

\section{El móvil de las guerras menores no es la destrucción material. Normalmente es un proyecto relacionado con el desarrollo social, económico y político de la gente. Es de importancia primaria que el mayor beneficio se derive de los aspectos psicológicos de la situación. Esto implica un estudio serio de la gente y de su desarrollo racial, político, religioso y mental (p. 5l, traducción propia).}

Este tipo de contrainsurgencia concibe la totalidad del paisaje como un campo de batalla y convierte a toda su sociedad en combatientes. Sobre todo, requiere de mapas de geografía humana para lograr sus objetivos. Los autores nos relatan cómo la influencia de este modelo creció en el contexto de la invasión a Irak y, posteriormente, influyó en el diseño de las Expediciones Bowman.

Para el aparato militar estadounidense, las nuevas amenazas proliferan en espacios abiertos y no regulados, caracterizados por una falta de derechos de propiedad. En este sentido, sólo la propiedad privada puede garantizar la seguridad y la paz. Para ello debe crearse un catastro universal y transparente que muestre quién es propietario de qué tierra. Así, el proyecto México Indígena respondía claramente a los intereses militares estadounidenses actuales: por un lado, probar la posibilidad de utilizar a científicos sociales para recolectar información y, sobre todo, construir un catastro que le permitirá monitorear transferencias de propiedad a nivel mundial, especialmente en regiones indígenas, barrios de escasos recursos y entre grupos organizados, todos estos considerados posibles amenazas militares.

En cuanto a la vertiente indígena, los autores la ubican en el surgimiento de la "etnocartografía" en Canadá a partir de la década de 1970, entre los grupos indígenas dene, cree e inuit. Esta iniciativa buscó documentar la ocupación y uso tradicional de los territorios para formular demandas de títulos de propiedad frente al avance de los gobiernos canadiense y estadounidense sobre el Ártico para el control de yacimientos petroleros.

En contraposición con el modelo contrainsurgente desarrollado a partir de la experiencia de ocupación en Nicaragua, en Canadá los "mapas biográficos" consistieron en la recolección de actividades de los grupos indígenas realizadas por ellos mismos, sus percepciones de la historia y el significado de sus territorios tradicionales. Para el caso de Chiapas, Evon Vogt retomó esta metodología en el marco del Proyecto Harvard. Esta tradición de mapeo se extendió y enriqueció, lo que contribuyó a generar una discusión amplia sobre la situación de explotación y marginación de las poblaciones y grupos indígenas del continente americano.

En 1971 tuvo lugar la Declaración de Barbados para denunciar el colonialismo interno en los países latinoamericanos con población indígena. Asimismo, se estableció una agenda para la liberación de los pueblos indígenas. De acuerdo con Bryan y Wood, un aspecto clave de este momento fue la transformación del concepto de "hábitat" en el concepto de "territorio", para subrayar los vínculos del colonialismo interno y externo y sus efectos sobre las poblaciones indígenas.

En este contexto de expansión del mapeo como arma de lucha de los pueblos y grupos indígenas y surgimiento de una agenda de liberación y defensa de los territorios indígenas, el ejército de Estados Unidos anunciaba la creación de una unidad nueva: la Dirección de Investigación de Operación de Guerras Pequeñas (Small Wars Operation Research Directorate, SWORD por sus siglas en inglés). Su objetivo era proveer al ejército con la investigación e inteligencia necesarias para el combate en guerras por el territorio. Este giro 
en la agenda militar estableció que las nuevas guerras se implementarían contra los pueblos indígenas y sus territorios.

Paralelamente, en 1989 la ONU y la OIT reconocieron el territorio como un derecho de los pueblos indígenas. En este contexto de reconocimiento, el mapeo asumió un sentido político nuevo, contribuyendo a la articulación de luchas por la tierra y los recursos bajo los conceptos de territorio y autonomía. Sin embargo, las nuevas luchas indígenas de la década de 1990 no se tradujeron necesariamente en la descolonización pronosticada. En cambio, anunciaron la utilización del mapeo indígena en la implementación de nuevas formas de gobierno, es decir, nuevas estrategias para gobernar las luchas por la tierra.

A partir de este momento se inauguraron dos vías para gobernar los territorios indígenas: proyectos de desarrollo y de conservación, en la mayoría de los casos con el apoyo de organizaciones no gubernamentales internacionales como la Fundación Ford, la Agencia de los Estados Unidos para el Desarrollo Internacional (USAID por sus siglas en inglés) y el Banco Mundial. Ambos tipos de proyectos se convirtieron en estrategias de seguridad o de contrarrevolución de cara a las demandas territoriales indígenas, a las cuales buscaron neutralizar.

De acuerdo con Bryan y Wood, en este contexto tiene lugar la transformación del objeto del mapeo de "territorio" a "propiedad", reemplazando el énfasis en la autonomía con el lenguaje del mercado y el gobierno de la ley. También las referencias a los derechos indígenas, la autodeterminación y el autogobierno se desdibujaron. Esta transformación colocó al Estado en una posición privilegiada para dirimir conflictos territoriales, facilitando en muchos casos el despojo de tierras indígenas. Las nuevas estrategias de gobierno de los territorios consisten en relaciones contractuales, en las cuales, a cambio de reconocimiento, los grupos indígenas deben comprometerse a conservar el ecosistema y proteger la biodiversidad. Según estos autores, los proyectos Corredor Biológico Mesoamericano y el Plan Puebla Panamá se inscriben en este contexto.
Y, mientras tanto, en México se discutía el Plan Mérida y se ponía en marcha el Programa de Certificación de Derechos Ejidales y Titulación de Solares (PROCEDE), un programa para regularizar las tierras colectivas bajo el argumento de asegurar los derechos de propiedad, cuya implementación requirió de mapeos a todo lo largo y ancho del país. Sin embargo, este programa ha resultado en la incorporación de tierras indígenas al mercado a través de su registro. En teoría, el proyecto México Indígena revelaría los impactos del PROCEDE en las comunidades indígenas, al mapear sus territorios y compararlos con los registros del PROCEDE para identificar errores y discrepancias. El proyecto comenzó en la Huasteca Potosina, pero obtuvo más financiamiento y se expandió a la sierra de Oaxaca, una zona caracterizada por sus conflictos agrarios y la dificultad para mapearlos. La historia de la Sierra de Juárez está estrechamente relacionada con la organización en contra de empresas productoras de papel, proyectos conservacionistas y, más recientemente, empresas mineras. En este contexto, los habitantes de la Sierra de Juárez en Oaxaca vieron en el proyecto México Indígena la posibilidad de contar con tecnología para tener mejor control sobre sus tierras y recursos y defenderlos de los proyectos extractivos en ciernes. La elaboración de un mapa de su territorio fue vista como un medio para su defensa.

Con el paso del tiempo, los habitantes identificaron los vínculos del proyecto con el aparato militar estadounidense. En marzo de 2009 una de las localidades emitió una denuncia pública contra el proyecto y demandaron que se les regresara toda la información obtenida. Peter Herlihy, el encargado del proyecto, nunca hizo mención de las conexiones de éste con el ejército de Estados Unidos. En todo caso, señaló que cualquier interés militar en el proyecto era puramente circunstancial (p. 143). Tampoco cumplió con la promesa de capacitarlos para realizar sus propios mapeos y darles equipo para dicha tarea. Y mucho menos entregó a las comunidades de la Sierra de Juárez toda la información obtenida a través del proyecto. 
A partir de una investigación crítica ampliamente documentada sobre el carácter político de los mapas y el mapeo, Bryan y Wood insisten en que se trata de "armar el mapa", es decir, usarlo críticamente y con conciencia para transformar el mundo. Para los autores, la utilidad y el potencial de los mapas radica en que las comunidades y grupos tengan pleno control sobre su realización, y el poder de decidir con quién compartirlos y cuándo utilizarlos. Asimismo, insisten en que es clave preguntarse cuál es la lógica detrás delmapeo, ya que denada sirvequelos gruposy comunidadesindígenas elaboren sus propios mapas si no se analiza críticamenteel contextoespecíficode su producción.
Finalmente, este libro es una invitación a preguntarnos sobre nuestro papel como investigadores y nuestra responsabilidad en torno al trabajo de investigación que realizamos. Nos invita a cuestionar constantemente los procesos de generación de conocimiento, específicamente para qué sirve y a quién beneficia. También nos recuerda que éste tiene consecuencias más allá de la academia y que, mal utilizado, puede perjudicar a las poblaciones más vulnerables y marginadas. Y apunta a la urgente necesidad de generar mecanismos de vigilancia dentro de la academia para evitar que se repitan casos como el del proyecto México Indígena. 